\title{
ERYTHROGENESIS IMPERFECTA
}

\author{
BY \\ I. A. B. CATHIE \\ From the Hospital for Sick Children, Great Ormond Street, London
}

(Received for Publication March 23, 1950)

A proper functioning of the red cell precursors in the bone marrow is essential for the maintenance of an adequate number of circulating red blood corpuscles, and there are several well-recognized ways in which the normal production of erythrocytes may be upset. The mechanism of the derangement is clearly understood in some cases, but in others the aetiology is quite unknown.

Various terms containing the words aplastic and hypoplastic are in common use to define the anaemias of childhood, and not only are these words often confused but sometimes they are applied to the peripheral blood and sometimes to the state of the marrow, so that a given description of an anaemia may be entirely at variance with the pathological process at work.

Aplastic anaemia, usually involving all the marrow elements, has been reported some 150 times (Whitby and Britton, 1946). In classifying the so-called aplastic anaemias, however, Rhoads and Miller (1934), besides describing the truly aplastic marrow, recognized a type in which the marrow was ' full ' of precursors of a primitive variety presumably incapable of maturing. An aplasia due to marrow exhaustion is occasionally seen as the result of a prolonged maturation factor deficiency or a haemolytic process. Whitby and Britton refer to six cases in the literature of total aplasia of the marrow erythroblastic elements, and a similar but periodic lack of marrow erythroblasts has been recently described, in which an allergic factor appears to play a part (Gasser, 1949).

A peripheral pancytopenia rather similar to the blood picture in aplastic anaemia is sometimes seen, and is thought to be due to the production by the spleen of a substance inhibitory to the bone marrow. Again, some poisons, infections, and drugs appear to have a direct depressant action on one or other of the bone marrow elements, causing a dysfunction, hypoplasia, or aplasia with consequent peripheral deficiency.

In contradistinction to these better recognized anaemias a group of five cases was reported by Diamond and Blackfan (1938; 1944) in which there were normal white cells and platelets with a peripheral red cell anaemia. There was no reticulocytosis, although the marrow erythroblasts were only moderately depressed, and as the condition was recognized early in infancy Diamond and Blackfan called it congenital hypoplastic anaemia. They were probably not the first observers of the condition, as Josephs reported two somewhat similar cases in 1936. It is referred to by Gasser (1949) as 'chronic idiopathic erythroblastopenia with aplastic anaemia (type Josephs-BlackfanDiamond).' Other cases, which from the descriptions appear to have been the same, have been reported by Kohlbry (1941), Rubell (1942), and Robson and Sweeney (1948); in these also a moderate to severe hypoplasia of the marrow erythroblasts was noted. None of these authors was able to indicate any causal factor for the condition, which on several counts is different from the better recognized non-regenerative anaemias.

The purpose of the present communication is to place on record five similar cases of anaemia, accompanied by erythroblasts in the marrow but no reticulocytosis. In spite of the necessity for repeated transfusions practically from birth both physical and mental development have been normal. A salient feature of the cases has been that only the peripheral red cells are depressed, granulocytes, lymphocytes, and platelets at all times being normal. The features of the condition are described in some detail because the rarity of the condition may be more apparent than real, and it might be more frequently recognized.

\section{Features of the Disease}

Of the five cases tentatively diagnosed as congenital hypoplastic anaemia, one went abroad and has been lost sight of. The remaining four have been observed for periods from one to five and a half years. There were three girls and two boys. There has been nothing in any history to suggest a familial element.

Age of Onset. Two of the children came under observation for pallor at the age of 3 weeks, one 
at 4 weeks, while the remaining two were first seen at the ages of 6 and 12 weeks respectively. In each of the first three cases anaemia as a late result of Rhesus incompatibility was suspected, but this was shown not to be the cause. The early age of onset has led to these cases being designated as congenital.

Diagnosis. This is based on a recurring anaemia of a normocytic normochromic type, such as is seen in true aplastic anaemia, without reticulocytosis. Reticulocytes are either absent or less than $0.01 \%$ as a rule, the highest proportion observed in any of the cases being $0.8 \%$. Late normoblasts in the peripheral blood are not uncommon, as many as 1,200 per c.mm. having been seen. Platelet counts, on the other hand, have always been normal. Granulocytes and lymphocytes also have always been normal, and have responded to the usual infections in the expected way, granulocytosis accompanying pyogenic infection while one patient who contracted whooping cough showed the characteristic lymphocytosis.

Serial bone marrow examinations have shown a variable picture. Two cases have shown an erythroid hypoplasia at most times, and although originally the red cell precursors were fairly plentiful they now appear to be approaching exhaustion. In two cases erythroblastic elements have been within normal limits, while in the fifth case they have on every examination been hyperplastic, being $50-70 \%$ of the marrow cells counted. The myeloid series and megakaryocytes have always appeared normal, and, as judged by observations on the peripheral blood, react normally.

Clinically there is little to be found in these children with the exception of pallor. The spleen is not palpable, except after transfusion, and so far no clinical signs have been detected which are more than evidence of anaemia. A point which may prove of importance is the remarkable similarity of the facies of the patients. All have had tow-coloured hair, snub noses, thick upper lips, rather wide-set eyes, and an intelligent expression (Figs. 1-4). This may be fortuitous, but it is interesting to observe that the photograph of Robson and Sweeney's (1948) patient shows the same features.

All the standard laboratory investigations have failed to bring this condition into line with any known pathological process. Red cell fragility tests on the patients and their families have on many occasions been normal. Evidence for a haemolysin has been sought in vain, repeated direct and indirect Coombs tests being negative. The DonathLandsteiner reaction has been negative, as have attempts to demonstrate lysins by varying $\mathrm{pH}$ and temperature. An indirect van den Bergh test as high as $2.5 \mathrm{mg}$. per $100 \mathrm{ml}$. has been seen occasion- ally, but usually this test has shown figures within normal limits. It will be appreciated that in view of the failure of these children to manufacture their own red blood corpuscles laboratory tests are in effect carried out on transfused donor cells. One child, of blood group B, has been maintained with group $O$ blood, so that the peripheral corpuscles are not agglutinated with anti-B serum, although his serum still agglutinates group A cells. Examination of the urine has shown no increase in urobilinogen or urobilin, and the naked eye appearance of the faeces is normal, as are the microscopy and biochemistry.

Prognosis. As the condition becomes longer in duration the effects of the prolonged anaemia manifest themselves. There is an apical systolic heart murmur, the liver enlarges, and the skin of our oldest child has taken on a slightly dusky hue. Some of these effects may be due, as suggested by Blackfan and Diamond (1944), to haemosiderosis consequent upon the repeated transfusions. Little is known of the remote prognosis. The possibility that the condition is a prodromal stage of leukaemia has been constantly borne in mind, but is becoming more remote as the children grow older without the appearance of atypical marrow cells. Of Blackfan and Diamond's five cases, two apparently recovered spontaneously, one a year after splenectomy. Oneg died of septicaemia, while the other two were alive, one having reached the age of 11 . The four cases we have kept track of are all developing normally apart from their anaemia, and the oldest is at present $5 \frac{1}{2}$ years of age.

The technical problem of transfusing a child whose peripheral veins have all been tied off becomes increasingly difficult, and we have had in two cases to resort to the direct injection of packed cells into the external jugular vein. It seems likely that this unavoidable necessity for rapidly overloading the circulation, combined with the damage which the heart musculature must have suffered from the prolonged anaemia, will eventually lead to a transfusion disaster.

Treatment. In common with other authors we have found no haematinic or other drug has had any effect upon the progressive anaemia or has influenced the failure of reticulocytosis. All forms of liver, given by mouth and parenterally, folic acid, vitimin $B_{12}$, and varying preparations and amounts of iron have been ineffective, as have arsenic and the trace elements such as copper, cobalt, and manganese. Owing to the lack of veins we have only been able to try an intravenous iron preparation on one child, without effect. Latterly we have realized that with the likelihood of eventual siderosis iron should be withheld after its initial trial. In 


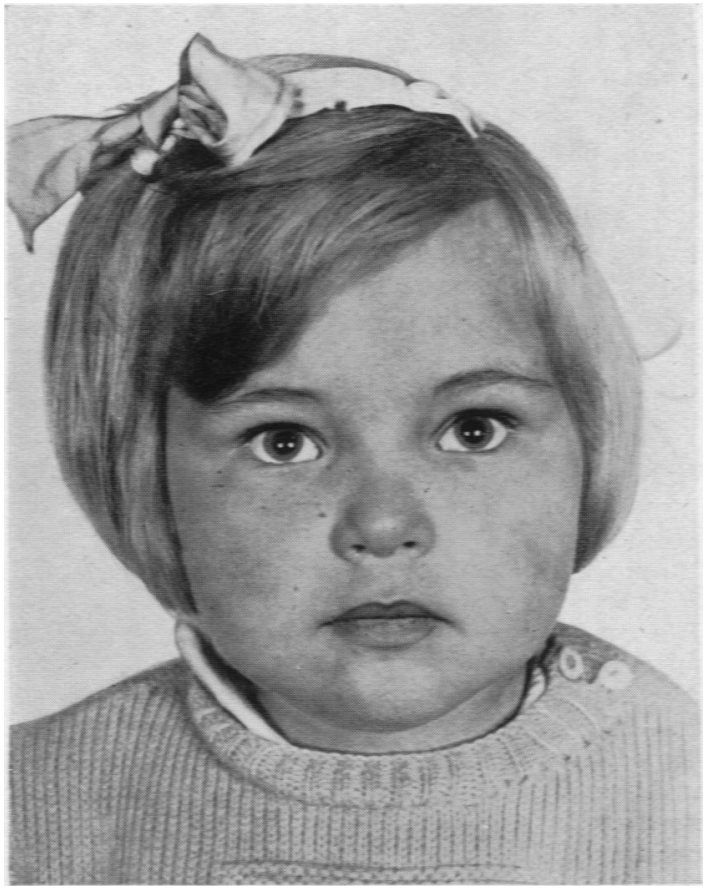

Fig. 1.-E.B., girl now aged $5 \frac{1}{2}$ years.

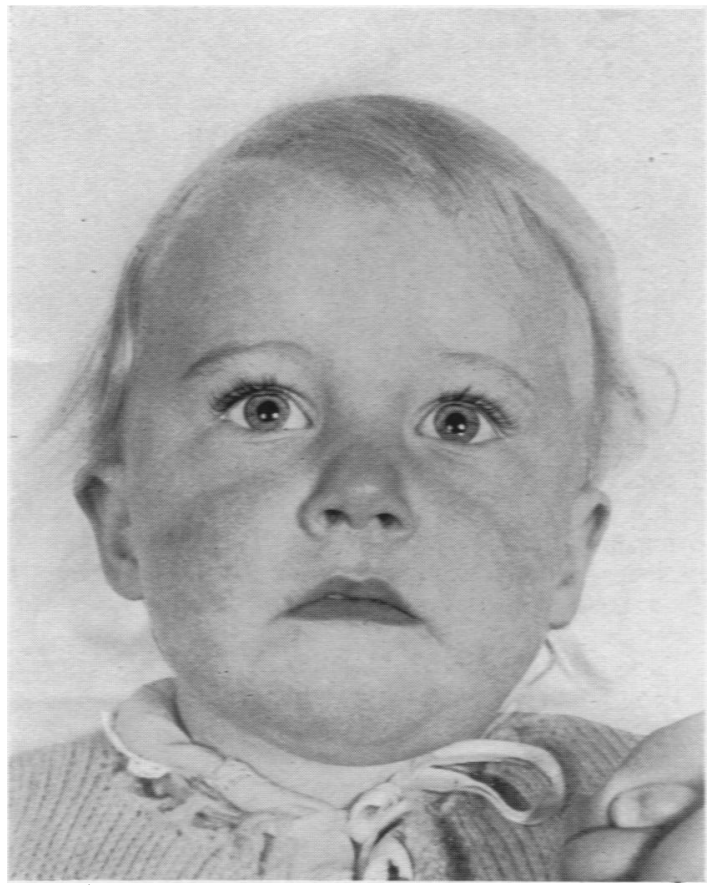

FiG. 3.-C.T., girl now aged 2 years.

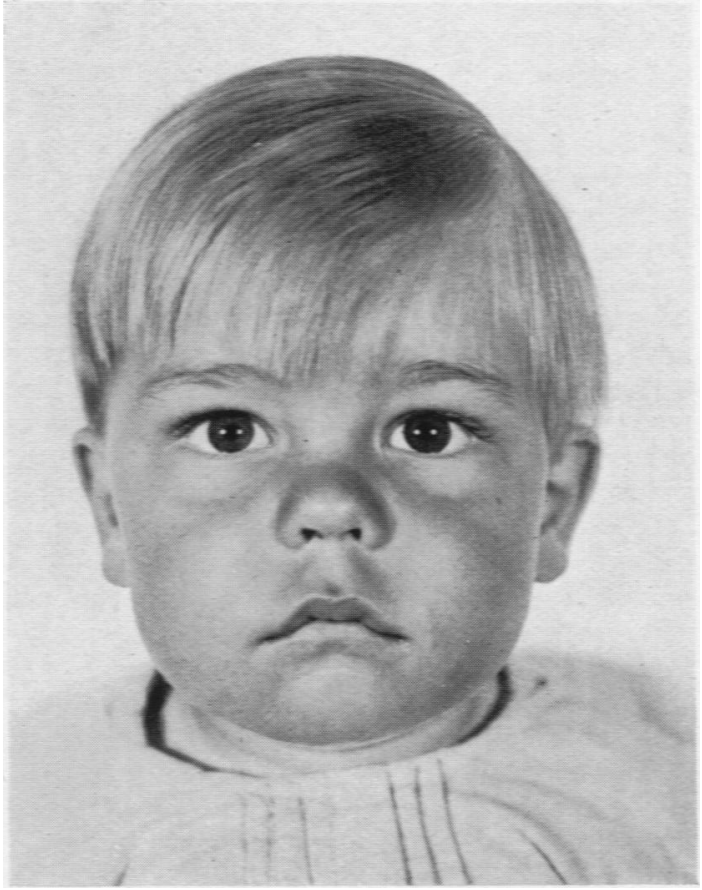

FiG. 2.-J.D., boy now aged $3 \frac{1}{2}$ years.

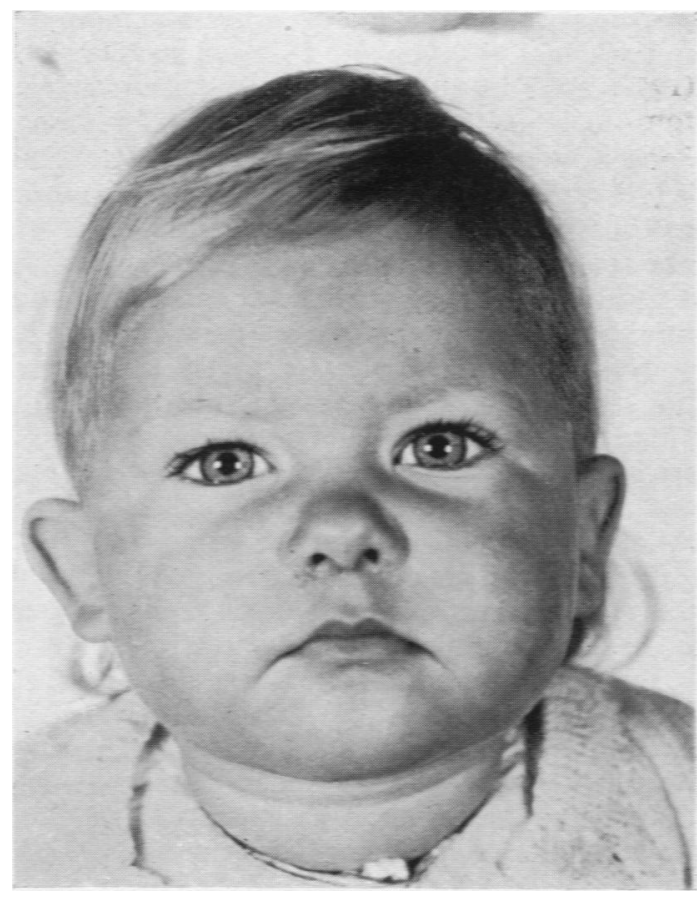

Fig. 4.-M.A.P., girl now aged $2 \frac{1}{2}$ years. 
any case, sufficient for immediate needs is supplied with the transfusions.

The various vitamins have been tried in high doses on one or other of the children without effect. It has been suggested that nicotinamide is the vitamin responsible for reticulocyte maturation, and two patients were reinvestigated from this point of view, but no reticulocytosis was obtained.

In view of the facial similarity of our patients and the possibility that some endocrine imbalance was present, and bearing in mind the reticulocytosis which may follow the administration of thyroxin to cretins, we have given, quite empirically, thyroxin, antuitrin, insulin, parathormone, adrenalin, testosterone, and stilboestrol. None has had any effect.

It has been postulated that a reticulocytogenic factor might be required for reticulocytosis. Accordingly, plasma was obtained from an adult with pernicious anaemia undergoing treatment with liver, whose blood showed a reticulocytosis of $57 \%$. On two successive days $25 \mathrm{ml}$. of this were injected intravenously into one of our anaemic children whose weight was $24 \mathrm{lb}$. Daily reticulocyte counts at the time and during the following two weeks showed no rise. Short-wave diathermy to the long bones was similarly shown to be ineffective in two cases.

Of Blackfan and Diamond's two cases which underwent spontaneous remission, one recovered a year after splenectomy, although the authors were sceptical of the part it played. Estren and Dameshek (1947) and Dacie and Gilpin (1944) found splenectomy to be of benefit in refractory anaemia of the Fanconi type, and Whitby and Britton (1946) found it to be beneficial in aplastic anaemia. One of our patients, therefore, had her spleen removed. During a convalescence accompanied by chest complications and a leucocytosis the peripheral normoblast count rose to 3,000 per c.mm. for a few days, but there was no corresponding reticulocytosis. This splenectomy was entirely speculative. It was not thought that 'hypersplenism' was likely to be the cause of erythropoietic depression alone, and in view of the one poor result of splenectomy the remaining children have not had their spleens removed.

The discouraging results reported with the transfusion of various types of bone marrow have led us not to try this form of therapy.

The replenishment of the peripheral red cells with donor cells as fresh as possible has been the only method of keeping these children alive. In view of the likely effects of the prolonged anaemia it is clearly desirable that the peripheral count should not be allowed to fall too far before transfusion. We should like to be able to avoid haemoglobin levels of less than $70 \%$, but unfortunately all the children live at considerable distances from London, and we have had to aim at a reduction of haemoglobin to $50 \%$ before blood replenishment. Such low levels, frequently lower before transfusion can be undertaken, cannot but be harmful in the long run.

The following is the history of one of these children showing the typical picture of the condition, and it illustrates most of the salient features and forms of therapy tried.

\section{Case History}

E.B. (Fig. 1) a girl, was born on March 28, 1945, of unrelated, healthy British parents. There was no family history of significance. One sister, aged 14 years, and one brother aged 4, were both normal.

There was no neonatal jaundice: the infant was breast fed for six months.

She was first noticed to be pale at 3 weeks of age, but remained free from symptoms and thrived until 3 months old, when she passed blood in her motions once and was taken for medical examination. Extreme pallor was observed, the haemoglobin being $24^{\circ}$. A blood transfusion raised this to $\mathbf{8 0}^{\circ}$. Three more transfusions were given in the next two months. After the third transfusion she developed otitis media with a discharge from the right ear, which cleared up in a few days. On September 29, 1945, she was admitted to the Hospital for Sick Children for investigation, five weeks after the last transfusion. Her right ear began discharging again on the day of admission.

On examination she was seen to be a well-nourished rather fat child, very pale, with a slight lemon yellow tint. The liver was not enlarged, the spleen just palpable, and no enlargement of lymph nodes. The right ear was discharging. No other abnormality was found.

BloOD Examinations: R.B.C.s, 1.33 millions; haemoglobin, $30 \%$ (Sahli) or $4 \cdot 2$ g. per $100 \mathrm{ml}$. Colour index, 1-13. M.C.D., 7-1 4 . W.B.C.s, 17,700 per c.mm. (polymorphs $10^{\circ}$, stab forms $34^{\circ}$, lymphocytes $54^{\circ}$, eosinophils $2^{\circ}$ ). No premature forms seen. Late normoblasts, 170 per c.mm. Reticulocytes, $0 \cdot 8^{\circ}$. Platelets, 216,000 per c.mm. Mother and child both group $O\left(R_{1} r\right)$ CDecde. No atypical antibody present in the maternal serum.

Bleeding time, 2 min. $30 \mathrm{sec}$; clotting time, $2 \mathrm{~min}$. $30 \mathrm{sec}$. Van den Bergh test direct, negative; indirect, $2.5 \mathrm{mg}$. per $100 \mathrm{ml}$. Wassermann and Kahn reactions negative; Mantoux test, 1/1,000, negative.

The marrow counts over a period of four years are tabulated.

A blood transfusion of $500 \mathrm{ml}$. raised the red count to 4.86 millions and the haemoglobin to $100 \%$. During the next six weeks there was a steady decline in the blood count, despite various therapeutic measures, and there was no rise in the reticulocy te count above $0.8^{\circ} \%$ on any occasion. The child was given iron up to $30 \mathrm{gr}$. daily (the preparation used contained copper, cobalt, and manganese); liver by injection and proteolysed liver by mouth, vitamin B complex; vitamin C: and thyroxin. 
TABLE

E.B. Marrow Counts

\begin{tabular}{|c|c|c|c|c|c|c|c|c|c|c|c|}
\hline \multicolumn{3}{|l|}{ Date } & $4 \cdot 10 \cdot 45$ & $31 \cdot 10 \cdot 45$ & $9 \cdot 1 \cdot 46$ & $1 \cdot 2 \cdot 46$ & $9 \cdot 3 \cdot 46$ & $1 \cdot 11 \cdot 46$ & $6 \cdot 5 \cdot 47$ & $2 \cdot 7 \cdot 48$ & $3 \cdot 1 \cdot 49$ \\
\hline Premyelocytes & . & $\cdots$ & & & & 3 & 3 & & & & 3 \\
\hline Myelocytes & . & $\cdots$ & 3 & 10 & 1 & 2 & 2 & 1 & 1 & 1 & 3 \\
\hline Metamyelocytes & . & $\cdots$ & 1 & 4 & 5 & 18 & 10 & 7 & 2 & 3 & 6 \\
\hline Stab forms .. & . & $\ldots$ & 23 & 14 & 3 & 5 & 9 & 7 & 10 & 12 & 5 \\
\hline Polymorphs .. & . & .. & 6 & 15 & 4 & 5 & 7 & 4 & 10 & 4 & 1 \\
\hline Lymphocytes .. & . & .. & 18 & 27 & 72 & 43 & 49 & 67 & 55 & 60 & 58 \\
\hline Monocytes .. & $\cdots$ & . & & & & 2 & 1 & 1 & & 2 & \\
\hline Haemocytoblasts & $\cdots$ & $\cdots$ & 1 & & 1 & & & & & & \\
\hline Pro-erythroblasts & . & .. & 3 & 10 & 8 & 6 & 1 & & 5 & 1 & 2 \\
\hline Early normoblasts & $\cdots$ & . & 1 & 12 & 3 & 7 & 5 & 2 & 10 & 2 & 2 \\
\hline Late normoblasts & . & .. & 44 & 7 & 3 & 9 & 15 & 11 & 7 & 13 & 20 \\
\hline Myeloid/erythroid & ratio & .. & $1 / 1 \cdot 5$ & $1 \cdot 5 / 1$ & $1 / 1 \cdot 1$ & $1 \cdot 5 / 1$ & $1 \cdot 4 / 1$ & $1 \cdot 5 / 1$ & $1 / 1$ & $1 / 1 \cdot 2$ & $1 / 1 \cdot 2$ \\
\hline
\end{tabular}

As her ear continued to discharge it was thought that this focus of infection might be depressing her marrow. As a mixed growth of coagulase-positive Staph. aureus and pneumococci was obtained on culture a ten-day course of penicillin was given, but this had no effect on the aural discharge or the downward course of her erythrocyte count. The white count was 27,000 with $69 \%$ polymorphs, and on October 19,1945 , her mastoids were opened and mucopus was found in both.

By November 13, 1945, the red cell count had fallen to $2 \cdot 5$ millions without reticulocytosis, and she was transfused again.

She developed an abscess in one mastoid scar on November 25, 1945, and on December 8 started an attack of pneumonia which was cut short with sulphamezathine. Apart from these incidents the only change was a monotonously regular fall in the blood count which necessitated transfusion every four to six weeks.

Other Investigations. Van den Bergh (16.10.45) indirect $1.5 \mathrm{mg}$. per $100 \mathrm{ml}$.; (13.11.45) $0.4 \mathrm{mg}$. Blood cholesterol level, $95 \mathrm{mg}$. per $100 \mathrm{ml}$. Erythrocyte fragility normal on three occasions. No spherocytosis. The red cells were never found to be sensitized to antihuman globulin serum (Coombs, Mourant, and Race, 1945). Cold agglutinin titre 1 in 4 at $8^{\circ} \mathrm{C}$. on one occasion. The faeces showed a trace of occult blood on one occasion but were repeatedly negative subsequently. No increase of urobilinogen in the urine. No free $\mathrm{HCl}$ after an alcohol test meal, but free $\mathrm{HCl}$ appeared within half an hour after histamine.

Other treatment at this time included $\mathbf{H C l}$, adrenalin and epinephrin, and varying types of liver preparation by mouth and injection, all without producing reticulocytosis.

The patient was discharged, and since has been admitted every six to ten weeks for transfusion.

In March, 1947, she had an attack of pneumonia, which was accompanied by a leucocytosis of 30,000 per c.mm. and was brought under control with penicillin and sulphamezathine. In November, 1947, her spleen was removed. No accessory spleens were found. She had post-operative bronchitis with leucocytosis. In the week following operation the peripheral normoblasts rose from 300 to 3,000 per c.mm., falling during the next week to 170 . The peripheral reticulocyte count during the month following the splenectomy was never as high as $1 \%$. All the routine blood tests at this time were materially the same as previously, and the red count continued to fall.

While in hospital for transfusion in March, 1948, she developed a unilateral parotitis which cleared up with penicillin. On this occasion she was given a course of short-wave diathermy to the long bones, without reticulocytosis or any visible effect.

During the admission in October, 1948, her liver was found for the first time to be palpable. At this time she was given antuitrin G. $1 \mathrm{ml}$. on alternate days for a fortnight, without any notable effect.

In March, 1949, the tonsils, which had been inflamed for the previous six months, were removed. At the same time the adenoids were removed and both maxillary antra were washed out, pus being found in one of them. The removal of these toxic foci improved the general health of the child without affecting the persistently falling 


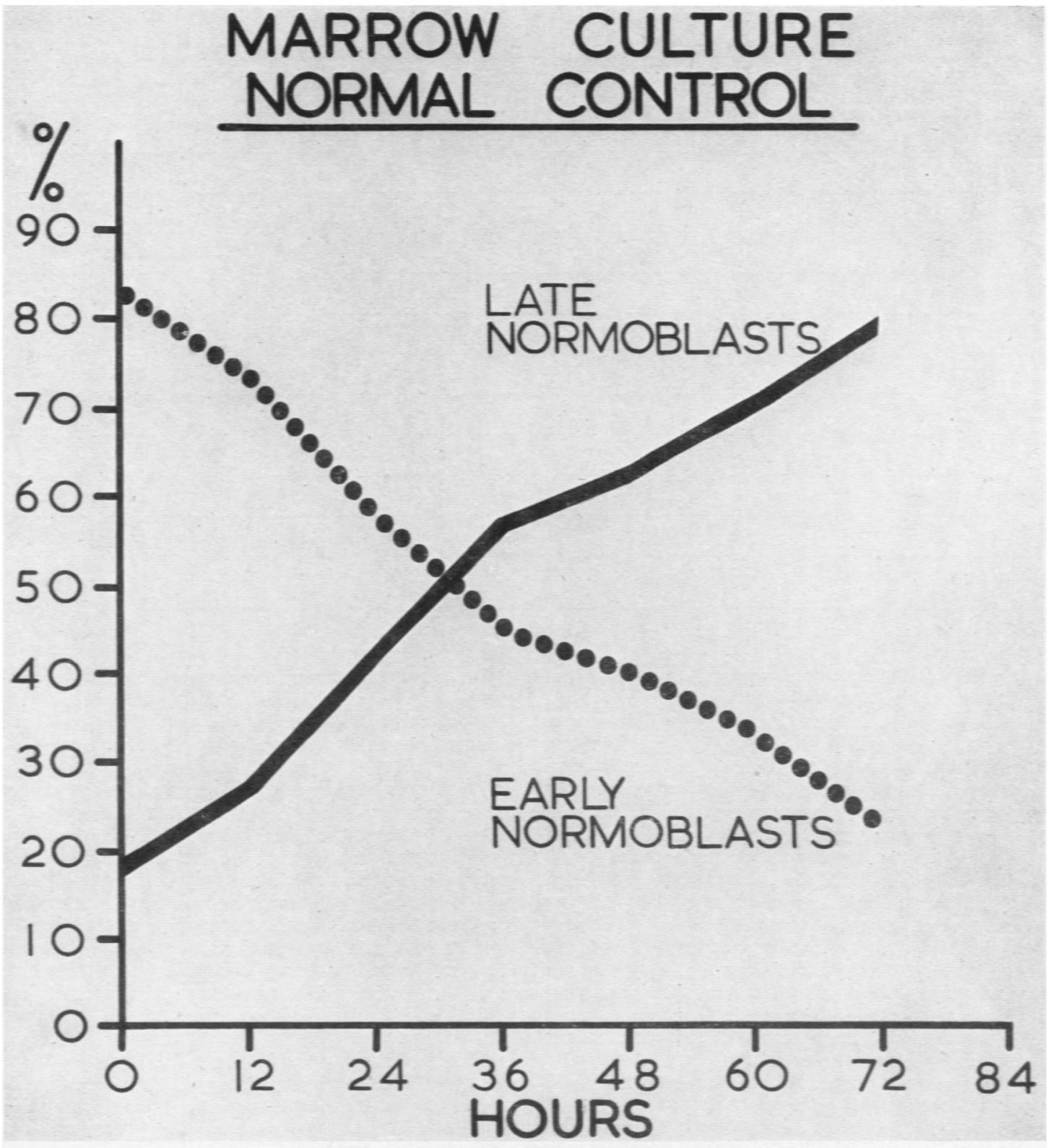

FIG. 5.

blood count. At the same time a leucocytosis of some 20,000 fell to 12,000 per c.mm.

Since the tonsillectomy no trouble has been encountered until the time of writing. During the past few years various haematinics such as folic acid and vitamin $B_{12}$ have been tried as they became available; the only form of treatment of any avail has been blood transfusion. In this particular child there are now no usable peripheral veins, and transfusion with packed cells has to be given into the external jugular vein. As she becomes bigger and needs greater amounts of blood more numerous transfusions must be given at each admission, and after each the heart and liver enlarge.

At the age of 5 years and 2 months she is a well grown and intelligent girl of $47 \mathrm{lb}$. (expected weight $40 \mathrm{lb}$.). She throws off infection readily, but till now has shown 


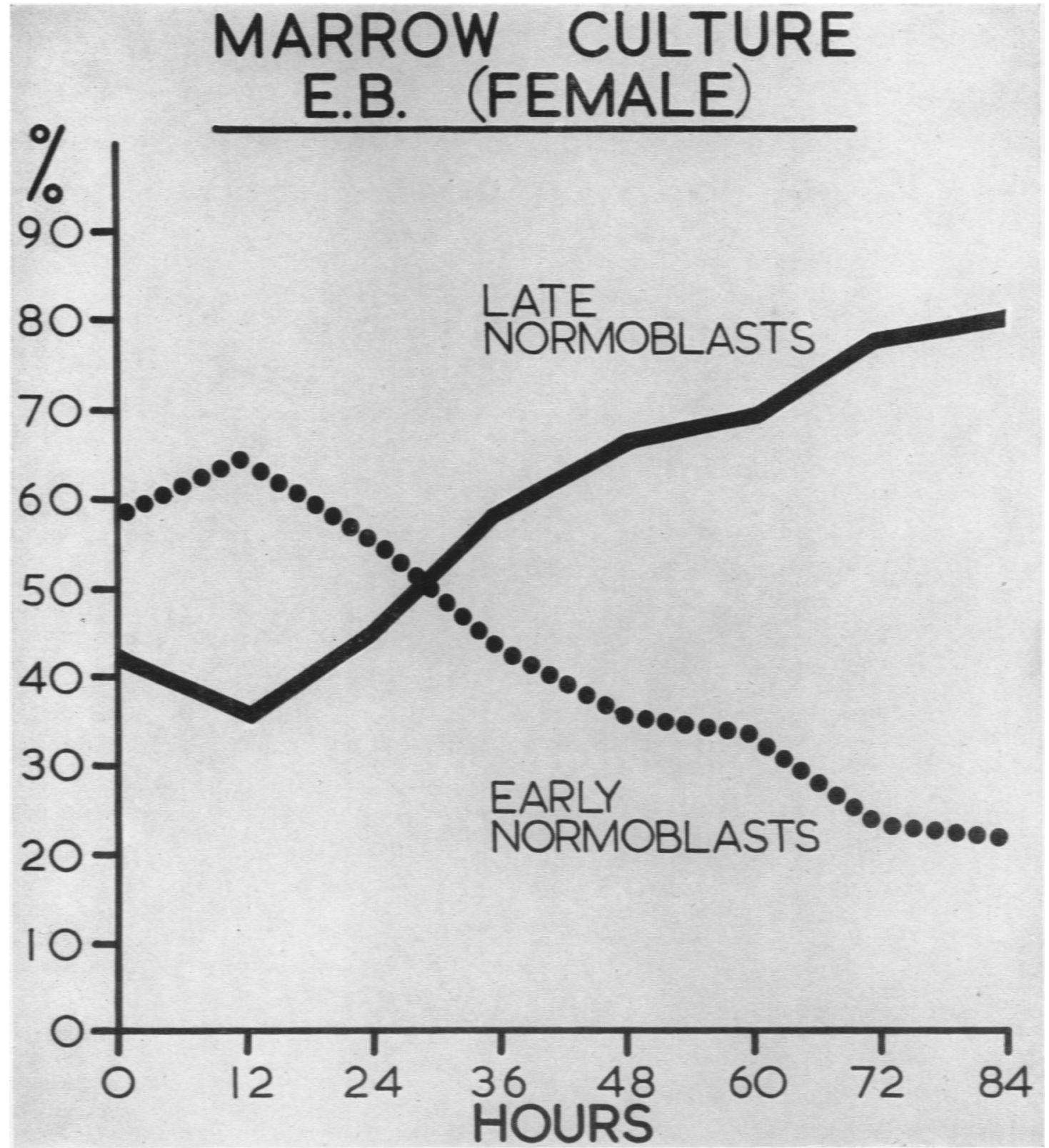

FIG. 6.

no sign of regenerating more than insignificant amounts of her own red corpuscles. It appears that her prognosis is related to the increasing technical difficulty of transfusing her, and there is always the possibility of an acute infection occurring at a time when the blood count is low.

A table of marrow counts is included. Marrow smears were at all times abundantly cellular, with megakaryocytes in normal numbers. The figures show that although there is an increase in lymphocytes there were also myeloids and red cell precursors on approximately normal proportions, with a myeloid erythroid ratio fairly constant around 1 .

\section{Marrow Cultures}

Marrow aspirate taken into a nutrient medium may be incubated up to three days, and by smears 


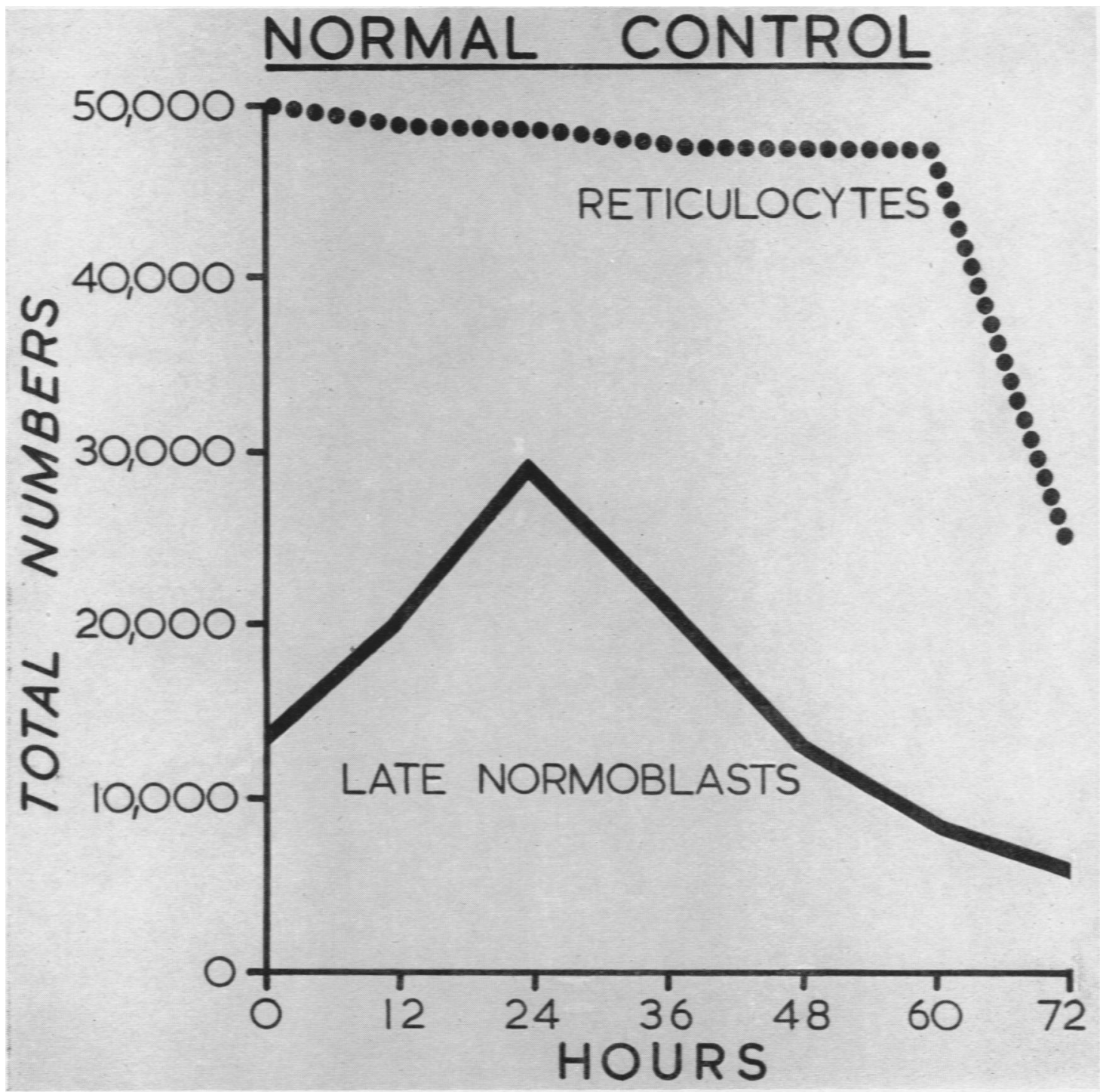

Fig. 7.

made serially during this time maturation of the marrow cells may be observed. The technique we have used was that described by Astaldi and Tolentino (1949), in which under aseptic conditions marrow is aspirated into a mixture of heparinized patient's own plasma and Tyrode's solution.

It seemed possible that this method of marrow examination might throw some light on our cases of anaemia, and after some normals had served to establish a base line and perfect the technique the marrow of three of the cases was investigated. All three showed what could be seen in the ordinary marrow smears, namely, that normal maturation from pro-erythroblast to fully haemoglobinized normoblast took place, but that at the late normoblast stage no further maturation to the reticulocyte occurred. This was in contradistinction to the behaviour of a normal marrow, where maturation from the late normoblast through the reticulocyte to the adult erythrocyte was apparent.

Fig. 5 shows typical maturation curves in a normal marrow, in which the earlier normoblasts are 


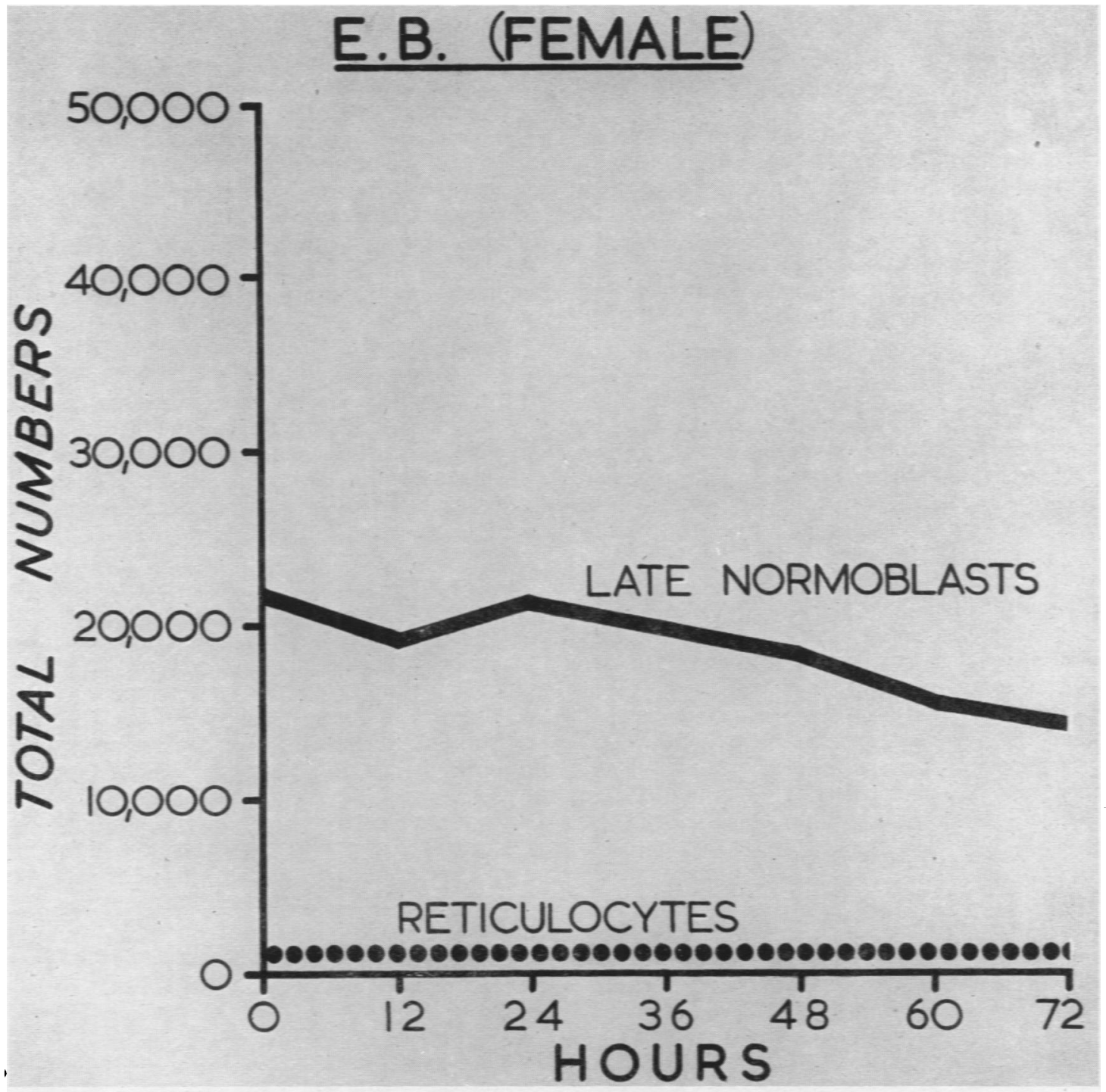

FIG. 8.

gradually replaced by late normoblasts, manifested when eight-hourly counts are done on the cultured marrow. For the sake of clarity pro-erythroblasts are not shown separately, but are included with the early normoblasts. Fig. 6 shows the maturation of red cell precursors in a case of congenital anaemia, and it is plain that maturation is essentially similar to the normal curves of Fig. 5. The curves are constructed from the percentages of total erythroblasts counted.

Figs. 7 and 8 show the difference in reticulocyte behaviour between a normal marrow and that from congenital anaemia. There would be no point in expressing late normoblasts and reticulocytes in terms of percentage in the anaemia case, as such a graph would consist of straight lines at more than $99 \%$ and less than $1 \%$. Therefore estimations of total numbers per c.mm. were made and drawn graphically. Fig. 7, from a normal marrow, shows the sort of numbers of late normoblasts and reticulocytes seen, although these absolute counts vary widely from marrow sample to sample and 
according to the amount of haemolysis which takes place during incubation. Fig. 8, from the case of anaemia described, illustrates the failure of reticulocyte production, the actual counts lying usually between 50 and 500 .

In two of the cases of anaemia further marrow cultures were made in which the nutrient fluid was prepared with fresh normal plasma, in the hope that we might be supplying some missing maturation factor; in neither case was the failure of reticulocytosis affected. It was not felt worth while to enrich the nutrient medium with isolated haematinics, because they have consistently failed to be effective in vivo.

\section{Discussion}

It must be confessed at once that the diagnosis of so-called congenital hypoplastic anaemia begs the issue and is made by a process of exclusion. In view of the lack of positive pathology this is not surprising; in the only necropsy on record Blackfan and Diamond (1944) were unable to find anything, apart from considerable siderosis, to correlate with the anaemia.

The condition under discussion differs from the usual aplastic anaemias and the familial anaemia of Fanconi's syndrome (1927) in that these show a general marrow hypoplasia with reduction of all the blood-forming elements, whereas in congenital anaemia only the peripheral red cells are affected. There is no familial aspect in the recorded cases. Two of our five cases are only children, and there are six siblings of the other three who are in all respects normal. These cases do not resemble periodic erythroblastopenia (Gasser, 1949), in that some red cell precursors are always present, nor are they like the 'full marrow' type of aplastic anaemia (Rhoads and Miller, 1934), where all the cells are primitive. In the pancytopenias due to hypersplenism the spleen is usually enlarged and the condition responds well to splenectomy, while in our case in which splenectomy was reluctantly performed the response was negative, as it was to any other form of treatment. In effect, the lack of red cell regeneration aligns our cases with the six referred to by Whitby and Britton (1946) of total absence of erythroblastic tissue in the marrow. The only reservations to this are that reticulocytes, although extremely scanty, have seldom been wholly absent, and that two reported cases, at least, appear to have undergone spontaneous recovery (Blackfan and Diamond, 1944).

Aetiology. Poisons may be immediately dismissed as the cause of lack of blood regeneration on account of the age at which pallor was first noted and the fact of breast feeding by healthy mothers.
Further, the duration of the condition and length of periods of stay in hospital, where the progress of the anaemia in no way abated, should exclude the possibility of any extraneous factors.

The infections to which these children seem prone have been considered as a possible marrow depressant, but recovery from these has never been accompanied by amelioration of the blood condition or by reticulocytosis. In accordance with the findings of others, notably Diamond and Blackfan (1938) and Rubell (1942), the anaemia appears to play no deleterious role in recovery from infection.

In considering the possible causes of the condition we were bound to be struck by the common facies. We have seen this facies in other diseases, but all our cases of anaemia have had it, as had the case of Robson and Sweeney (1948). If this facial resemblance means anything it might be due to an endocrine cause or might be genetically determined. Against an endocrine aetiology is the fact that, unlike the treatment of cretins with thyroxin, in no case has the blood picture been influenced by the various endocrine preparations which have been tried empirically. Admittedly, the whole endocrine, field has not been investigated, only thyroxinadrenalin, pituitrin, insulin, parathormone, stilboestrol and testosterone having been given. Against the genetic hypothesis is the normal foetal development and the complete absence of any family history in our five cases or in those in the literature. The cases of familial hypoplastic anaemia described by Estren and Dameshek (1947) were of the Fanconi type of anaemia with hypoplasia of all the marrow elements, and splenectomy was of some benefit.

The evidence for a maturation factor deficiency is equivocal. The normal maturation evident in marrow smears, as well as maturation to the late normoblast constantly seen in marrow cultures, argues against a deficiency factor, at least to the stage of development of the haemoglobinized normoblast. Also against the lack of some factor is the failure of response to any known haematinic. And if such a factor were present in the plasma it is remarkable that in the many hundreds of transfusions of fresh and stored blood which have been given to our five patients it has never been present in sufficient amount to affect the reticulocyte count. Further evidence against a deficiency factor is that when plasma, which is known to facilitate normal maturation and reticulocytosis of a normal marrow, is added to cultures of marrow from a case of congenital anaemia no reticulocytosis occurs. Two points are in favour of there being a maturation factor deficiency. First, these children are born normal, as far as we know, the earliest case having 
presented itself at the age of 3 weeks. This suggests that a factor might have been acquired from the maternal serum during gestation and that its supply fails following parturition. Secondly, in none of our cases has there been a complete lack of reticulocytes. At no time have there been enough to indicate participation in blood regeneration. But the fact that some, at least, of the normoblasts achieve the reticulocyte stage may indicate that a factor, as yet unknown, is present in sufficient amount to permit slight maturation, but insufficient to produce a physiological replacement of obsolete blood corpuscles.

A superficially attractive hypothesis to account for the failure of reticulocytosis is that the normoblasts, which have been found up to 1,200 per c.mm. peripherally, represent a premature discharge into the circulation before they have had time to mature to reticulocytes or erythrocytes. Against such a theory are the facts that their numbers do not vary with the degree of anaemia, that the normoblasts fail to mature in culture, and that, although there was a transient rise in the peripheral normoblast count following our one splenectomy, the rise was not sustained, nor was it accompanied by the reticulocytosis which was to be expected had the spleen been removing the normoblasts before maturation.

Nomenchature. The nomenclature of this type of anaemia is unsatisfactory. Refractory anaemia of infancy is clearly too non-specific, and the American workers have favoured the descriptive term congenital hypoplastic anaemia. The early onset of the disease and the marrow picture are responsible for the name. The condition does not appear to have been recognized at birth, but declares itself during the first few weeks or months of life. If, as they appear to be, the infants are born with a normal blood picture it will not be until some weeks of life have passed that the physiological destruction of the circulating red cells without replacement will draw attention to increasing pallor. The term congenital, therefore, may be fallacious. Hypoplastic, similarly, is not always an accurate description. While Kohlbry (1941) and Blackfan and Diamond (1944) noted moderate hypoplasia in their cases, and that of Robson and Sweeney (1948) showed gross erythroid hypoplasia, and two of our cases have also shown a moderate hypoplasia, this is not a constant finding. Among our cases of this disease two have at all times shown a cellular marrow in which, while there is a percentage lymphocyte increase, there are sufficient cells for us to feel that the absolute numbers of myeloid and erythroid cells are normal. That these numbers are presumably adequate is shown by the granulocyte response to infection. In our fifth case the erythroid cells were usually increased proportionally, the marrow appearance at times recalling that seen in haemolytic anaemia. If hypoplasia were all the story, one would expect a moderate erythroid hypoplasia to be productive of a moderately reduced reticulocyte response, whereas the erythroblasts present, even in reduced numbers, seem scarcely to mature at all. It seems, then, that as far as the marrow is concerned, at least, the term hypoplastic cannot be used for all cases. While hypoplastic might be used of the peripheral picture with justification it will not cover the discrepancy between the blood and the marrow. If some such term is necessary for the anaemia possibly the word non-regenerative should be used, as this would not automatically suggest that the marrow is deficient in cells.

Experience has shown that many of the so-called idiopathic anaemias are really secondary, their aetiology becoming manifest with the discovery of some missing factor, and it is probable that in the course of time some overaction or deficiency will be found to account for the anaemia of these patients. At present this factor, if such there be, is completely unknown. Yet the marrow pictures and cultures indicate unequivocally that the developmental hold-up lies between the late normoblast and reticulocyte stages. This hold-up is so clear as almost to resemble an inborn error of development on the part of the late normoblast. On account of the unsatisfactory nature of the term congenital hypoplastic anaemia, and by analogy with other known developmental errors, it is suggested that the condition be called erythrogenesis imperfecta. Reluctant as we are to introduce new terms into haematology, it is felt that erythrogenesis imperfecta, in the light of the experimental observations, conveys a truer word picture, and prejudices the issue less, than any of the other descriptive titles which have been applied to this distinctive form of non-regenerative anaemia of infancy and childhood.

\section{Summary}

Five cases of what has been called congenital hypoplastic anaemia are reported, and the history of one is described in detail.

The anaemia is characterized by failure of blood regeneration and reticulocytosis in spite of the presence of some erythroblasts in the marrow.

Attention is drawn to the similarity of the facies of the cases.

The results of marrow cultures are presented which indicate that red cell maturation fails at the late normoblast stage. 
The aetiology and lack of response to all forms of treatment except blood transfusion are discussed.

The term erythrogenesis imperfecta is proposed for the condition, as being less misleading than the other descriptive titles.

I am indebted to the physicians of the Hospital for Sick Children for access to their cases, Mr. D. Martin for the photographs, and Mr. P. J. Cull for the charts.

\section{REFERENCES}

Astaldi, G., and Tolentino, P. (1949). J. clin. Path., 2, 217 .

Blackfan, K. D., and Diamond, L. K. (1944). 'Atlas of the Blood in Children.' New York.
Coombs, R. R. A., Mourant, A. E., and Race, R. R. (1945). Lancet, 2, 15.

Dacie, J. V., and Gilpin, A. (1944). Archives of Disease in Childhood, 19, 155.

Diamond, L. K., and Blackfan, K. D. (1938). Amer.J. Dis. Child., 56, 464.

Estren, S., and Dameshek, W. (1947). Ibid., 73, 671.

Fanconi, G. (1927). Jahrb. Kinderheilk., 117, 257.

Gasser, C. (1949). Schweiz. med. Wschr., 79, 838.

Josephs, H. W. (1936). Medicine, Baltimore, 15, 307.

Kohlbry, C. O. (1941). J. Pediat., 19, 662.

Rhoads, C. P., and Miller, D. K. (1934). Amer. J. Path., $10,679$.

Robson, T., and Sweeney, P. J. (1948). Archives of Disease in Childhood, 23, 294.

Rubell, I. (1942). J. Pediat., 20, 756.

Whitby, L. E. H., and Britton, C. J. C. (1946). 'Disorders of the Blood.' London. 5th ed. 